\title{
Middle ear function in rheumatoid arthritis
}

\author{
J. N. ROSENBERG, D. A. MOFFAT, R. T. RAMSDEN, \\ W. P. R. GIBSON, AND J. B. BOOTH
}

From the Departments of Rheumatology and Otolaryngology, The London Hospital, Whitechapel, London

SUMMARY Using an otoadmittance meter the function of the middle ear was compared in $\overrightarrow{38}$ patients with rheumatoid arthritis (RA) and 30 matched controls with non-articular rheumatisin. Patients with pre-existing ear disease were excluded from the study. No subjects in either grotap showed hearing loss on pure tone audiometry, but otoadmittance abnormalities were recorded $\overrightarrow{\mathrm{f}}$ 16 of the RA (42\%) and in 2 of the control groups $(7 \%)$. The pattern of abnormality was similar in each case and indicated an increased laxity of the conducting system. The reason for this uof expected finding is unknown. There were no significant differences between the RA patients wifh normal or abnormal recordings as regards clinical or laboratory features or treatment.

The pathophysiology of the middle ear in RA is unclear. Both transient (Copeman, 1963) and permanent conductive deafness (Ransome, 1964) have been described in patients with RA. Other studies have suggested that sensorineural deafness, unrelated to drug therapy, may be more common in RA than in health (Goodwill et al., 1972; Heyworth and Liyanage, 1972).

Valuable objective information on the state and function of the middle ear structures is available to the otologist by the use of a conventional acoustic impedance meter. This can be thought of as a device which measures the degree to which the tympanic membrane and ossicular chain 'impedes' the passage of a sound wave entering the ear. It is commonly used to diagnose pathologies which stiffen or loosen the middle ear structures and to assess the pressure or detect fluid at that site. The otoadmittance meter is a research tool of similar, but more sophisticated design. However, instead of recording the degree to which sound is 'impeded' it measures the ease with which it is 'admitted' to the ear. Both impedance and admittance are determined by a number of factors. These are frictional effects, the stiffness of the drum and ossicular chain, and the mass of the latter. These component forces may be assessed more accurately by the otoadmittance meter than by the commercially available impedance meters. Recordings are made with the air pressure in the external auditory canal varying from positive through ambient to negative pressure. The effects of these

Accepted for publication February 8, 1978 Correspondence to Dr J. N. Rosenberg. pressure changes on sound energy flow may plotted on a tympanogram (Fig. 1).

Mass and stiffness are opposing forces. At low sound frequencies the mass effect is relatively sgaatil and stiffness is the dominant factor affecting seind energy flow. At high sound frequencies the mass effect becomes greater and a point will eventuma be reached at which these two forces cancel eaen other out. This is known as the resonating frequen of the ear. It occurs at about $800 \mathrm{~Hz}$ in health and is characterised by a marked notch on the tympanogram (Fig. 1, tracing C).

The otoadmittance meter employs a high frèquency probe tone stimulus $(660 \mathrm{~Hz})$ which is close to but below the normal resonating frequency of the middle ear. In health it is unusual for the resonatiog frequency to be reached and a notched tracing is not produced on the tympanogram (Fig. 1A). The reso ating frequency is reduced by loosening pathologigs such as hypermobility of the tympanic membrame due to healed perforations, or disruption of the ossicular chain, and increased by stiffening conditions such as otosclerosis (Lidén et al. 1971. Thus pathologies which reduce the resonating fre:quency to below $660 \mathrm{~Hz}$ will produce a notch on the $660 \mathrm{~Hz}$ tympanogram (Fig. 1B).

We report our observations on the tympans grams of patients with RA assessed by the ot:admittance meter.

\section{Patients}

A well characterised group of 38 adults with classicall or definite RA according to the America्d 


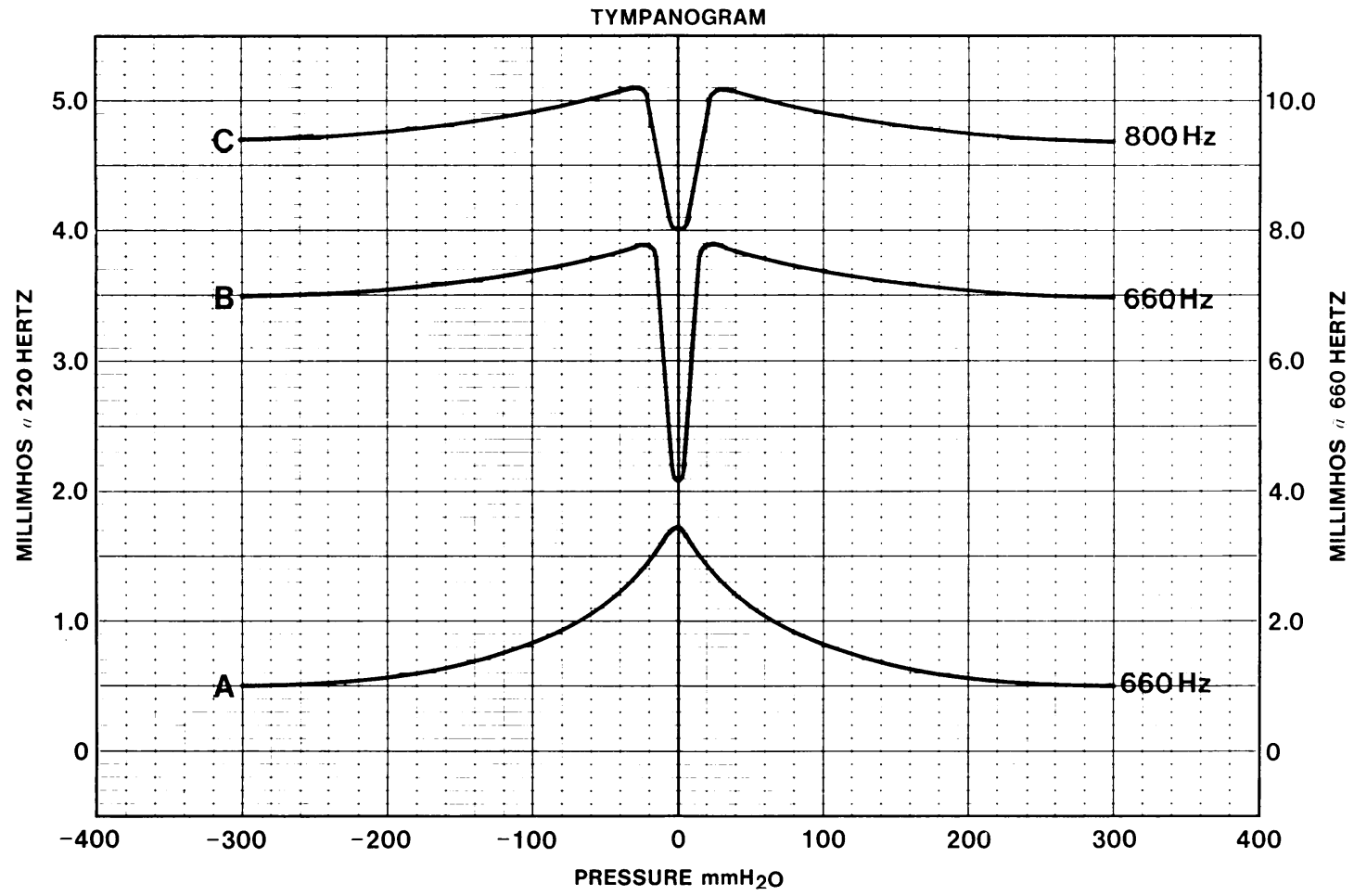

Fig. 1 Tympanogram demonstrating normal $660 \mathrm{~Hz}$ (A), $800 \mathrm{~Hz}$ (C), and abnormal $660 \mathrm{~Hz}$ (B) otoadmittance responses to air pressure variations between -300 and $+300 \mathrm{~mm} \mathrm{H}_{2} \mathrm{O}(-2.94$ to $+2.94 \mathrm{kPa})$.

Rheumatism Association criteria (Ropes et al., 1959) and a control group of 30 patients with non-articular rheumatism of similar age and sex distribution to the RA group were studied. The 68 patients had previously fulfilled the following criteria for inclusion in the survey: (1) no history of ear disease, (2) clinically normal tympanic membranes.

A detailed drug history was obtained in each case.

\section{Method}

Pure tone audiometry was initially carried out on all patients to assess their hearing thresholds. The 68 patients were then examined with the GrasonStadler 1720B otoadmittance meter. The air pressure gradient in the external auditory meatus was automatically varied between -300 to $+300 \mathrm{~mm} \mathrm{H}_{2} \mathrm{O}$ $(-2.94$ to $+2.94 \mathrm{kPa})$ at a rate of $15 \mathrm{~mm} \mathrm{H}_{2} \mathrm{O} / \mathrm{s}$ $(0.147 \mathrm{kPa} / \mathrm{s})$ in the study. Full technical details of this instrument have been described elsewhere (Moffat et al., 1977). All subjects were examined once only and their responses were automatically recorded on tympanograms.

\section{Results}

None of the 68 subjects had conductive or sensorineural hearing loss on pure tone audiometry. Abnormal otoadmittance responses were recorded in $16(42 \%)$ of the RA and in $2(7 \%)$ of the control groups $\left(\chi^{2} 9 \cdot 07, P<0.01\right)$. The abnormality which was similar in all 18 cases consisted of a wide notch on the $660 \mathrm{~Hz}$ tympanogram (Fig. 1B) characterising a loosening condition. Equivocal responses were obtained from a further 5 patients with RA who were excluded from analysis of the results. No significant differences were detected between those RA patients with or without an abnormal response as regards clinical or laboratory parameters (Table 1).

\section{Discussion}

The reason for the striking disparity between the RA and control groups is uncertain. The incidence of abnormal tympanograms in the controls corresponds with the findings of Lidén et al. (1974) and may be the result of small, healed perforations of the tympanic membrane which cannot be detected on routine clinical examination. 
Table 1 Analysis of clinical and laboratory findings in 33 patients with $R A$

\begin{tabular}{|c|c|c|c|c|c|c|c|c|c|}
\hline \multicolumn{6}{|l|}{ Median } & \multicolumn{4}{|c|}{ Incidence (\%) } \\
\hline $\begin{array}{l}\text { Tympano- } \\
\text { grams } \\
\text { (no.) }\end{array}$ & $\begin{array}{l}\text { Sex } \\
(M: F)\end{array}$ & $\begin{array}{l}\text { Age of onset } \\
\text { (years) }\end{array}$ & $\begin{array}{l}\text { Disease } \\
\text { duration } \\
\text { (years) }\end{array}$ & $\begin{array}{l}\text { Active joint } \\
\text { count }\end{array}$ & $\begin{array}{l}\text { ESR } \\
\text { (Westergen) }\end{array}$ & Nodules & $\begin{array}{l}\text { Rheumatoid } \\
\text { factor }\end{array}$ & Steroids & 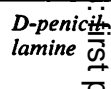 \\
\hline $\begin{array}{l}+16 \\
-17\end{array}$ & $\begin{array}{l}3: 13 \\
5: 12\end{array}$ & $\begin{array}{l}46 \cdot 5(31-66) \\
44 \quad(18-63)\end{array}$ & $\begin{array}{r}13(3-31) \\
6(1-33)\end{array}$ & $\begin{array}{l}13 \cdot 5(6-17) \\
11 \quad(5-13)\end{array}$ & $\begin{array}{l}58(15-113) \\
54(5-121)\end{array}$ & $\begin{array}{l}15 \\
12\end{array}$ & $\begin{array}{l}36 \\
36\end{array}$ & $\begin{array}{l}15 \\
15\end{array}$ & $\begin{array}{l}9 \\
9\end{array}$ \\
\hline
\end{tabular}

The presence of a response in the RA patients indicating a disturbance which increases the laxity of the conducting system and thus reduces the resonant frequency point is of interest. Rheumatoid involvement of the interossicular joints might be expected to produce an increase in the stiffness component of otoadmittance and thus increase the resonant point of the ear.

However, firm histological evidence of RA involvement of the interossicular joints is lacking (Gardner, 1972; Goodwill et al., 1972) and ankylosis of these joints may be unassociated with any clinical or audiometric disturbance (Etholm and Belal, 1974). Increased collagenolysis which may occur in RA (Etherington, 1977) could contribute towards the abnormal laxity of the conducting system.

Ototoxicity has to be considered in any study of the ear in RA. The ototoxic antirheumatic drugs are generally known to act on the inner ear. Salicylates, indomethacin, ibuprofen, phenylbutazone, and antimalarials have all been associated with sensorineural deafness (Ajodhia and Dix, 1976) No sensorineural abnormalities attributable to drugs were detected in any of our patients. There were also no differences between the small numbers of patients receiving systemic steroids or $D$-penicillamine (Table 1) both of which could theoretically increase the laxity of the conducting system by an effect on collagen metabolism.

The conducting system in RA is undoubtedly abnormal when assessed by otoadmittance. We have also noted similar tympanograms in 3 patients with ankylosing spondylitis without peripheral arthritis. Otoadmittance is an extremely sensitive technique which can reveal minimal pathophysiological changes in the conducting system. None of our patients had conductive hearing loss. Thus, we cannot comment on the deafness which others have attributed to rheumatoid disease. Our own and previous studies (Copeman, 1963; Ransome, 1964; Goodwill et al., 1972; Heyworth and Liyanage 1972) suggest that clinically significant conductive deffs ness is a rare phenomenon in RA.

We are grateful to Professor H. L. F. Currey and C. G. Barnes for allowing us to study patients under their care.

\section{References}

Ajodhia, J. M., and Dix, M. R. (1976). Drug induced de ness and its treatment. The Practitioner, 216, 561-570.

Copeman, W. S. C. (1963). Rheumatoid oto-arthritio British Medical Journal, 2, 1526.

Etherington, D. J. (1977). Collagen degradation. Annats of the Rheumatic Diseases, 36, Suppl. 2, 14-17.

Etholm, B., and Belal, A. (1974). Senile changes in the middle ear joints. Annals of Otology, Rhinology Laryngology, 83, 49-54.

Gardner, D. L. (1972). The Pathology of Rheumatoid Arthrit 1st. ed., p. 7. Edward Arnold: London.

Goodwill, D. J., Lord, I. J., and Knill Jones, R. P. (1977) Hearing in rheumatoid arthritis. Annals of the Rheumasc Diseases, 31, 170-173.

Heyworth, T., and Liyanage, S. P. (1972). A pilot survey hearing loss in patients with rheumatoid arthritis. Scandinavian Journal of Rheumatology, 1, 81-83.

Lidén, G., Harford, E., and Hallén, O. (1974). Tympaño metry for the diagnosis of ossicular disruption. Archives of Otolaryngology, 99, 23-29.

Lidén, G., Peterson, J. L., and Björkman, G. (1970). Tym panometry. Archives of Otolaryngology, 92, 248-257.

Moffat, D. A., Ramsden, R. T., Rosenberg, J. N., BootB, J. B., and Gibson, W. P. R. (1977). Otoadmittanee measurements in patients with rheumatoid arthritif. Journal of Laryngology and Otology, 91, 917-927.

Ransome, J. (1964). Rheumatoid arthritis and deafness. British Medical Journal, 1, 179.

Ropes, M. W., Bennett, G. A., Cobb, S., Jacox, R., an Jessor, R. A. (1959). Diagnostic criteria for rheumatoffe arthritis. Annals of the Rheumatic Diseases, 18, 49-53. 